\title{
ANALISA PERBANDINGAN KEKUATAN STRUKTUR BED MESIN BUBUT CNC KIRANA BPPT TERHADAP BED MODIFIKASI DENGAN MENGGUNAKAN SOFTWARE ANALYSIS
}

\section{COMPARATIVE ANAL YSIS OF STRUCTURAL STRENGTH OF THE BPPT KIRANA CNC LATHE BED AGAINST MODIFIED BED BY SOFTWARE ANALYSIS}

\author{
Amar Makruf T.F., Barep Luhur Widodo \\ Balai Teknologi Mesin Perkakas, Teknik Produksi dan Otomasi - BTMEPPO \\ Badan Pengkajian dan Penerapan Teknologi - BPPT \\ Gedung Teknologi 2, PUSPIPTEK, Tanggerang Selatan, Banten - 15314. \\ e-mail : amar.makruf@bppt.go.id, e-mail : barep.luhur@bppt.go.id
}

\begin{abstract}
Abstrak
Agar dapat bersaing dengan produk luar negeri, saat ini BT-MEPPOBPPT mengembangkan mesin perkakas nasional khususnya mesin bubut $\mathrm{CNC}$ dengan harga yang bersaing namun tidak mengurangi kualitas mesin yang akan dibuat. Aspek penting dalam merancang mesin bubut salah satunya adalah perancangan struktur bed yang mampu menahan beban statis dari komponen mesin bubut yang lain. Struktur bed yang dikembangkan oleh BT-MEPPO adalah memodifikasi desain bed yang lebih ringan dan dimensi lebih optimal sehingga mengurangi biaya produksi namun tetap memenuhi standard. Proses perancangan dilakukan menggunakan metode riset \& development untuk membandingkan analisa struktur desain bed secara umum dengan modifikasi desain bed sehingga didapat kriteria statik berupa defleksi dan tegangan von mises untuk memastikan desain modifikasi aman untuk digunakan.
\end{abstract}

Kata kunci: modifikasi, bed bubut CNC, defleksi, von mises

\begin{abstract}
In order to compete with import product, currently BT-MEPPO-BPPT develops machine tools especially CNC lathes with competitive prices but does not reduce the quality of the engine that will be made. An important aspect in designing a lathe is one of which is the design of a bed structure that is able to withstand static loads from other lathe components. The bed structure developed by BT-MEPPO is modifying the design of a lighter bed and more optimal dimensions so as to reduce production costs but still meet the standards. The design process was carried out using research \& development methods to compare the analysis of bed design structures in general with bed design modifications so that static criteria were obtained in the form of deflections and von mises stresses to ensure the modification design was safe to use.
\end{abstract}

Keywords: modification, CNC lathe bed, deflection, von mises

Diterima (received ) : 10 April 2019 , Direvisi (revised ) : 17 Juni 2019 ,

Disetujui (accepted) : 28 Juni 2019

\section{PENDAHULUAN}

Tujuan utama dari teknologi manufaktur adalah untuk memproduksi komponen yang sepresisi mungkin sesuai dengan desain teknik dalam waktu singkat dengan biaya yang murah ${ }^{1}$. Oleh karena itu perlu dikembangkan desain mesin perkakas yang 
murah dari segi biaya produksi namun tetap memenuhi standard mesin perkakas sesuai ISO 13041-1:2004 mengenai pengujian, akurasi, dan repeatability mesin bubut.

Masalah yang sering dihadapi dalam proses pengembangan mesin perkakas adalah pengujian secara fisik prototype mesin tersebut, karena proses tersebut membutuhkan waktu dan biaya yang tidak sedikit ${ }^{2}$. Pada Gambar 1 ditampilkan perbandingan antara proses pengembangan sebuah mesin secara konvensional dan dengan menggunakan software analysis atau bisa kita sebut virtual prototype.

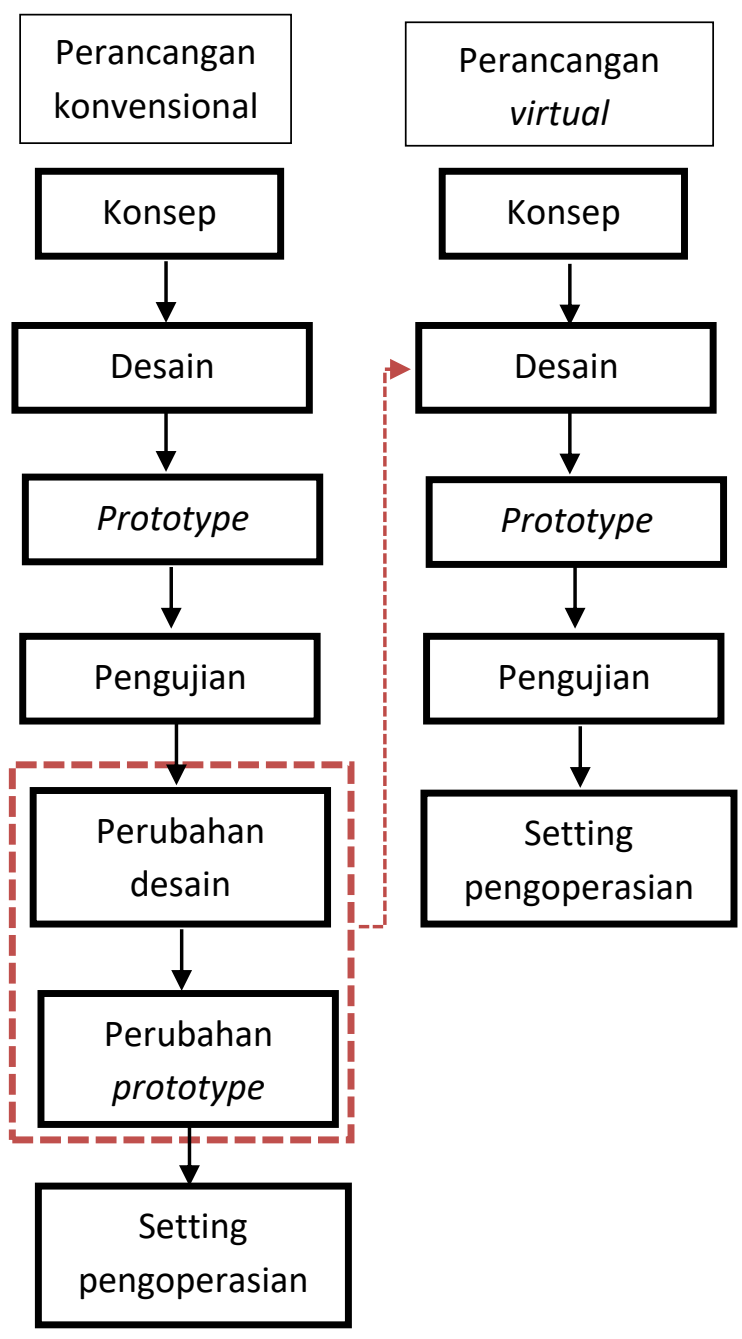

Gambar 1.

Perbandingan Perancangan konvensional dan virtual).

Software analysis menggunakan simulasi komputer menghasilkan pendekatan analisa secara komputerisasi terhadap hasil pengujian prototype secara langsung. Virtual prototype tersebut akan diuji dan dianalisa hingga mendapatkan hasil yang optimal atau sesuai dengan performa yang diinginkan, sehingga biaya dan waktu yang dikeluarkan dapat dikurangi jika dibandingkan dengan perancangan konvensional yang melibatkan proses penggantian desain dan penggantian prototype sebelum akhirnya mesin tersebut beroperasi3 ${ }^{3}$. Hasil dari simulasi virtual prototype tersebut dapat menjadi dasar dalam membuat dan menentukan spesifikasi desain prototype yang nantinya akan diuji performa mesin tersebut sebelum diproduksi.

Dengan menggunakan metode simulasi komputasi tersebut Balai Teknologi Mesin Perkakas, Teknik Produksi, dan Otomasi Badan Pengkajian dan Penerapan Teknologi (disingkat BTMEPPO - BPPT) melakukan proses riset \& development (pengembangan) dari desain bed mesin bubut Kirana yang sebelumnya pernah dibuat di BTMEPPO seperti pada gambar 2. Target dari pengembangan produk ini adalah harga yang lebih murah dan mempunyai kualitas yang sama dengan produk sejenis buatan luar negeri di pasaran, sehingga mesin bubut tersebut mampu bersaing dengan mesin buatan luar negeri.

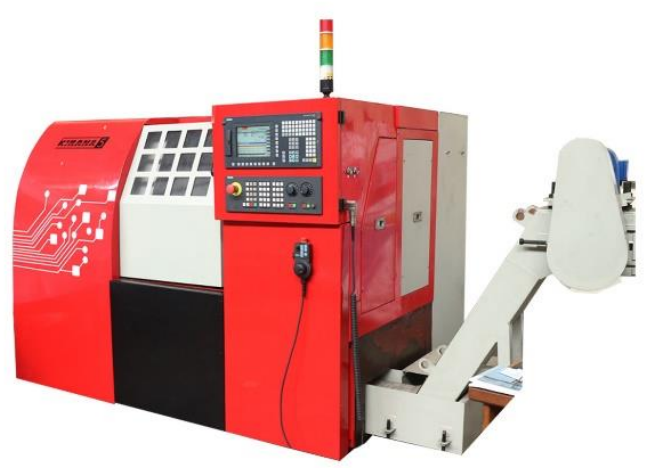

Gambar 2. Mesin bubut Kirana BTMEPPO-BPPT

\section{METODOLOGI}

Metodologi yang digunakan untuk menyelesaikan penelitian ini antara lain :

1. Studi Literatur

Penulis mencari dan mengkaji literatur yang sesuai dengan penelitian untuk memahami proses perancangan struktur bed mesin bubut CNC. Literatur yang dimaksud berupa jurnal, Handbook, dan sumber penelitian dari internet.

2. Pembuatan desain $C A D$

Desain CAD dibuat berdasarkan dokumen as built drawing dimana dimensi gambar menyesuaikan dimensi aktual. Sehingga gambar 
CAD yang akan dianalisa sudah sesuai dengan produk bed hasil proses machining.

3. Modifikasi dan optimasi desain Desain bed yang sebelumnya dimodifikasi dari segi ukuran dan strukturnya, modifikasi ini bertujuan untuk mengurangi biaya produksi namun tetap memenuhi standard pengujian ISO 13041-1:2004. Standard ini mengatur tentang mengenai pengujian, akurasi, dan repeatability mesin bubut.

4. Analisa pembebanan statik

Penulis menganalisa kekuatan struktur bed ketika menerima pembebanan statik yang sama dari berat komponen yang harus ditopang oleh bed tersebut 5 ).

5. Diskusi

Penulis melakukan diskusi setiap saat (jika diperlukan) dari awal penelitian sampai penelitian selesai dengan rekan satu tim peneliti dan berbagai pihak untuk menganalisa dan mencari solusi untuk menentukan langkah selanjutnya.

\section{HASIL DAN PEMBAHASAN Hasil Penelitian}

Penelitian ini dilakukan pada 2 bed yaitu bed Kirana dan modifikasi. Bed modifikasi merupakan bed Kirana yang dikurangi massa nya pada bagian atas dudukan headstock. Pengurangan massa ini bertujuan untuk mengurangi material dan biaya produksi. Pada gambar 3 terdapat kotak merah yang merupakan bagian yang dikurangi/ dihilangkan.

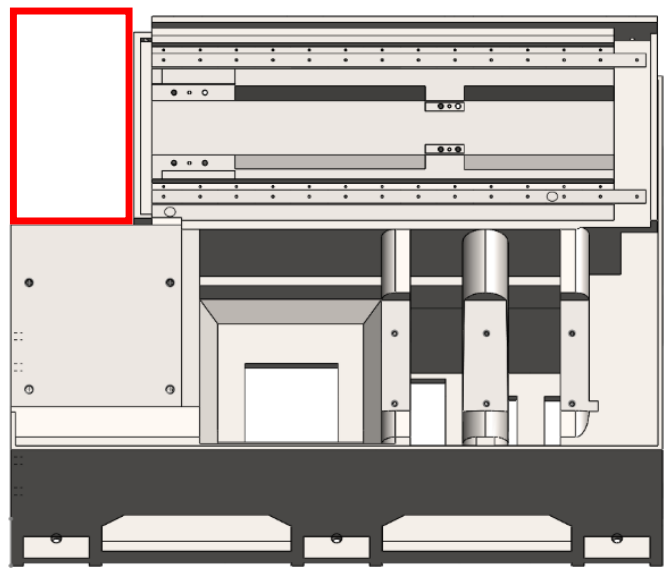

Gambar 3.

Bed modifikasi
Mesin bubut CNC secara umum terdiri dari 6 komponen utama, yaitu bed, tooling system, guideways, tailstock, headstock, dan motor penggerak ${ }^{6}$.

Tabel 1 berikut ini merupakan berat dari komponen utama mesin bubut CNC.

Tabel 1.

Berat Komponen Utama Mesin Bubut CNC

\begin{tabular}{llc}
\hline No & \multicolumn{1}{c}{ Komponen } & $\begin{array}{c}\text { Berat } \\
(\mathrm{Kg})\end{array}$ \\
\hline 1 & Headstock + motor & 375 \\
2 & Tooling system + Guideways & 350 \\
& Z Axis & 210 \\
3 & Tailstock + Guideways X Axis & 210 \\
4 & motor hidrolik + ball screw & 70 \\
\hline
\end{tabular}

Gambar 4 berikut merupakan pemosisian komponen mesin bubut CNC secara umum.

Dalam pembebanan statik ini akan dibuat beberapa asumsi sebagai kondisi batas untuk memudahkan proses perhitungan dan analisis, antara lain:

1. Pembebanan akibat berat komponen yang diterima oleh bed adalah dari tailstock, guideways. headstock, dan tooling system.

2. Gaya berat yang diterima oleh bed Kirana dan bed modifikasi besarnya sama dan terdistribusi merata/tidak pada satu titik pada bagian bed yang menerima pembebanan.

3. Nilai gravitasi $\mathrm{g}=10 \mathrm{~m} / \mathrm{s}^{2}$

Material bed menggunakan carbon steel FC 25 dengan yield strength $276 \mathrm{MPa}^{7)}$.

Keterangan :

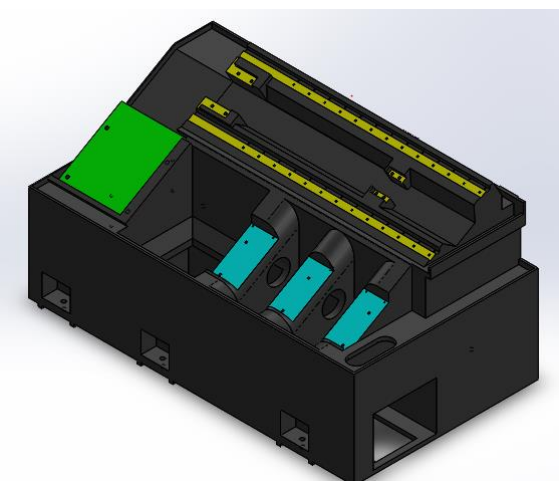

: Headstock + motor

: Tooling system + Guideways $Z$ axis

: Tailstock + guideways $X$ axis

Gambar 4.

Pemosisian komponen mesin bubut CNC 
Pada Gambar 5 berikut merupakan gaya pembebanan pada bed mesin bubut CNC.

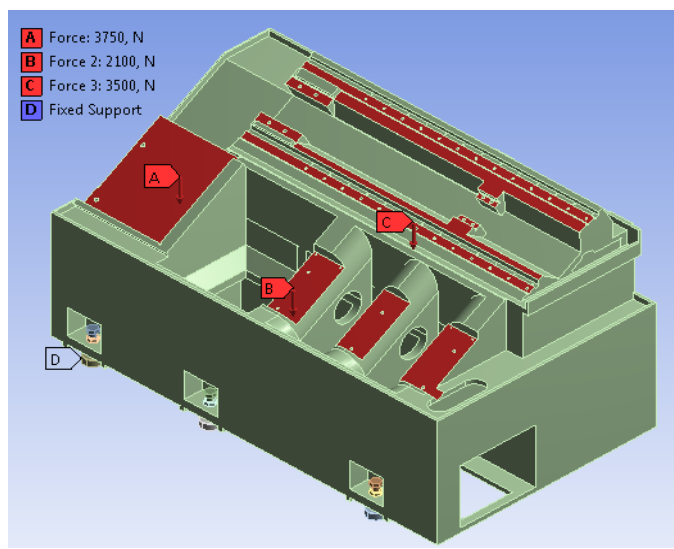

a)

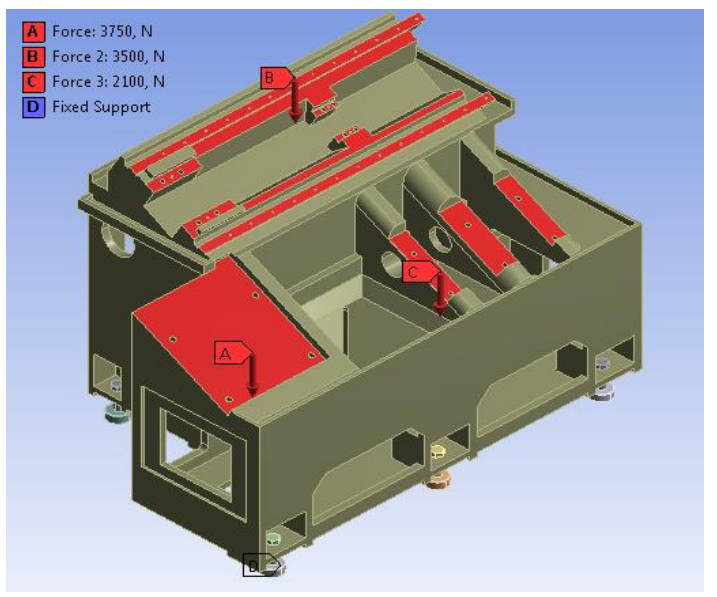

b)

Gambar 5.

Gaya pembebanan bed CNC, a) Bed Kirana, b) Bed modifikasi

Besar dan arah gaya yang diberikan seperti pada Gambar 5 diaplikasikan pada bed kemudian dilakukan analisis statik untuk melihat defleksi dan tegangan von mises untuk menganalisa apakah desain struktur tersebut mampu menahan beban yang diberikan ${ }^{8}$. Berikut merupakan hasil dari simulasi analisis statik.

\section{Analisis statik deformasi}

Pada Gambar 6 berikut adalah hasil dari analisis statik untuk melihat defleksi pada desain bed Kirana dan bed modifikasi.

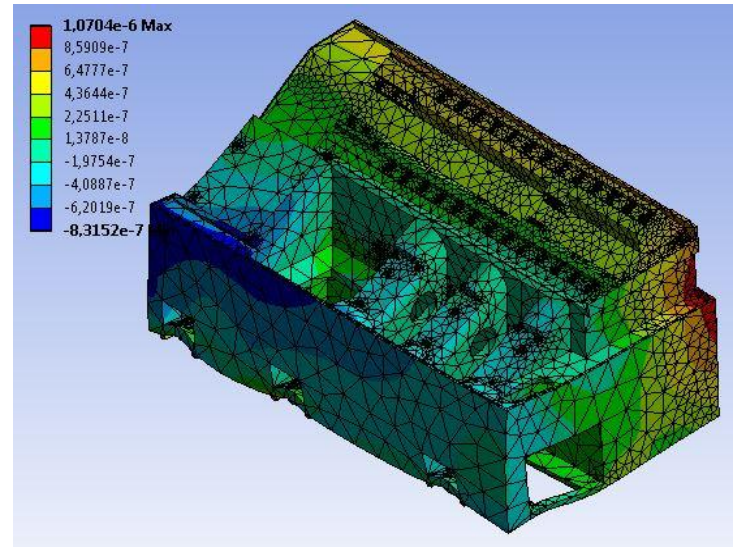

a)

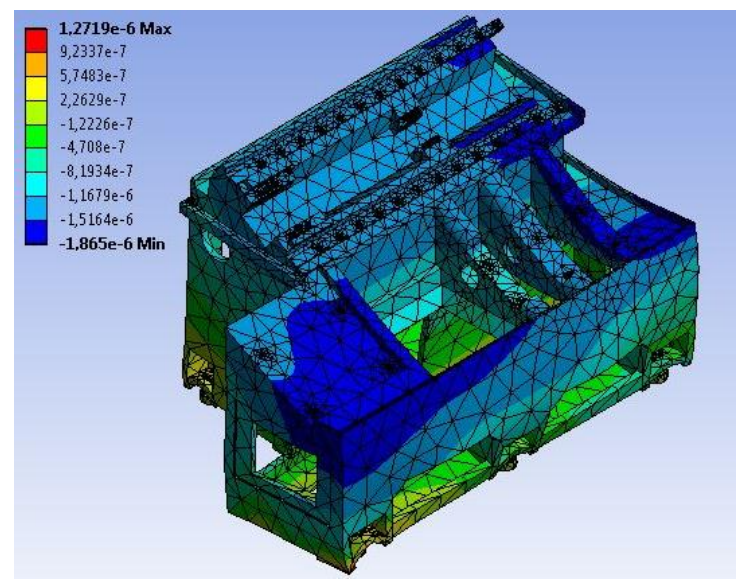

b)

Gambar 6.

Defleksi statik bed CNC, a) Bed Kirana, b) Bed modifikasi

2. Analisis statik Tegangan von mises

Pada Gambar 7 berikut adalah hasil dari analisis statik Tegangan von mises pada desain bed Kirana dan bed modifikasi.

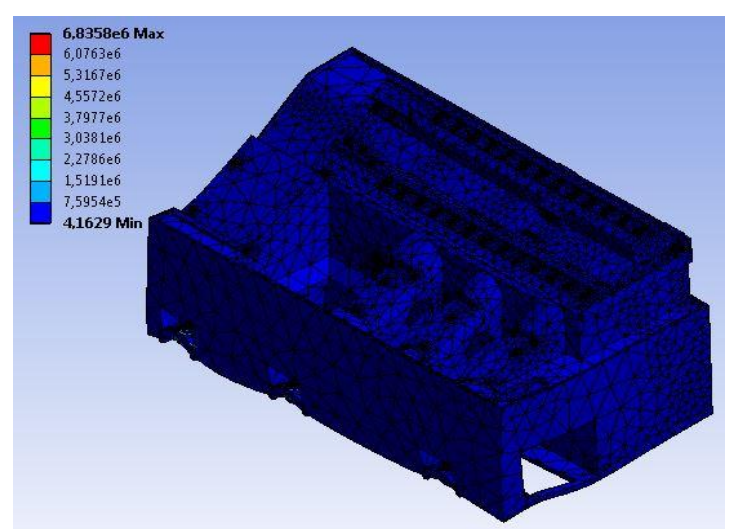

a) 


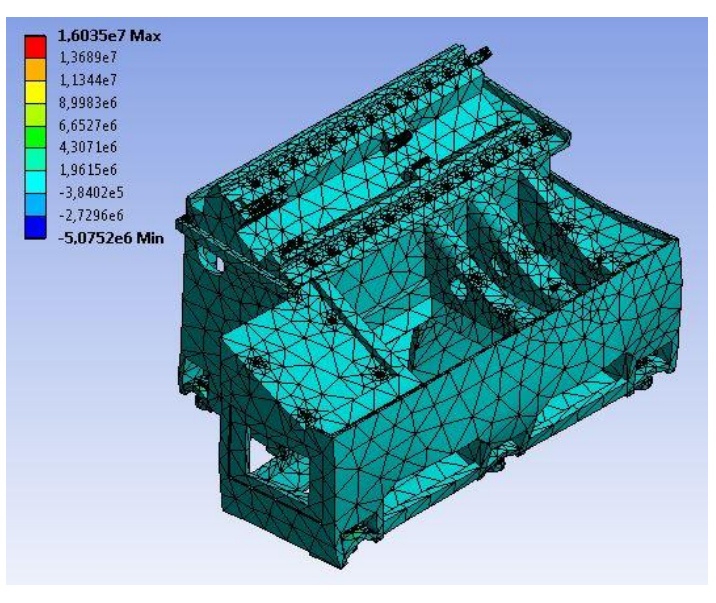

b)

Gambar 7.

Tegangan Von mises bed CNC, a) Bed Kirana, b) Bed modifikasi

\section{Pembahasan}

Dari analisis pembebanan statik tersebut, dapat ditampilkan dalam tabel 2 berikut :

Tabel 2.

Hasil Pembebanan Statik Bed

\begin{tabular}{lccc}
\hline $\begin{array}{c}\text { Desain } \\
\text { bed }\end{array}$ & $\begin{array}{c}\text { Berat } \\
(\mathrm{kg})\end{array}$ & $\begin{array}{c}\text { Defleksi } \\
\text { statik } \\
(\mu \mathrm{m})\end{array}$ & $\begin{array}{c}\text { Tegangan } \\
\text { von mises } \\
(\mathrm{MPa})\end{array}$ \\
\hline Kirana & 284 & 1,07 & 6,8 \\
Modifikasi & 208 & 1,2 & 16 \\
\hline
\end{tabular}

Analisa pembebanan statik bed kirana menghasilkan tegangan von mises sebesar 6,8 MPa hasil simulasinya ditunjukkan pada gambar $7 a$ dan desain bed modifikasi menghasilkan tegangan von mises sebesar $16 \mathrm{MPa}$ ditunjukkan pada gambar $7 \mathrm{~b}$, nilai keduanya masih dibawah yield strength material yang dipakai yaitu sebesar 276 $\mathrm{MPa}^{7}$ ), hal ini mengindikasikan bahwa kedua desain tersebut mampu untuk mendistribusikan pembebanan yang dialaminya dengan baik ${ }^{9)}$.

Dari aspek deformasinya untuk bed kirana mengalami defleksi statik maksimal sebesar $1,07 \mu \mathrm{m}$ ditunjukkan pada gambar $6 \mathrm{a}$, sedangkan untuk bed modifikasi mengalami defleksi maksimal sebesar 1,2 $\mu \mathrm{m}$ ditunjukkan pada gambar $6 \mathrm{~b}$, hal ini menunjukkan bahwa dari segi defleksi yang dialami, desain bed kirana mempunyai tingkat kekakuan yang lebih baik daripada bed modifikasi, walaupun dengan selisih yang tidak signifikan sebesar $0,13 \mu \mathrm{m}^{5}$.

Dari segi berat bed antara bed kirana dan modifikasi, bed modifikasi mempunyai berat yang jauh lebih ringan yaitu $208 \mathrm{Kg}$ sedangkan berat bed kirana $284 \mathrm{Kg}$. Selisih berat dari keduanya sangat signifikan yaitu 76 $\mathrm{Kg}$. Hal ini mempunyai pengaruh terhadap biaya produksi komponen bed yang jauh lebih murah dan masih aman jika digunakan menurut analisa struktur yang telah dilakukan.

\section{SIMPULAN}

Dari hasil dan pembahasan pada bab sebelumnya dapat disimpulkan bahwa desain struktur bed modifikasi masih aman menerima beban statik dari komponen mesin bubut yang lain, hal tersebut dapat dilihat dari hasil simulasi von mises yang ditunjukkan pada tabel 2. Tabel tersebut menunjukkan nilai tegangan von mises struktur bed modifikasi dibawah yield strength material carbon steel FC 25 dengan yield strength 276 MPa.

Ditinjau dari defleksi maksimal, desain struktur bed modifikasi tidak jauh berbeda dengan desain bed kirana/existing. Hasil simulasi menunjukkan selisih antara bed Kirana dan bed modifikasi tidak begitu signifikan, walaupun bed Kirana masih mempunyai tingkat kekakuan yang lebih baik.

Tujuan dari desain struktur bed modifikasi adalah dapat meminimalisir biaya produksi komponen bed yang merupakan material pengecoran. Perhitungan biaya pengecoran berdasarkan berat dari produk cor itu sendiri. Bed modifikasi mempunyai berat yang jauh lebih ringan, selisih berat antara bed Kirana dan bed modifikasi sangat signifikan yaitu 76 $\mathrm{Kg}$. Artinya dalam proses manufaktur pengecoran, biaya yang dapat dipangkas sebesar $76 \mathrm{Kg}$ untuk setiap produk bed yang dibuat.

\section{UCAPAN TERIMAKASIH}

Selama menyelesaikan penyusunan jurnal ini penulis telah banyak mendapat bantuan dari berbagai pihak, baik secara langsung maupun tidak langsung. Untuk itu, dengan segala kerendahan hati, penulis ingin menyampaikan ucapan terima kasih yang sebesar-besarnya kepada semua pihak yang turut membantu, khususnya :

1. Bapak Ir. Teddy Alhady Lubis, M. Eng selaku kepala Balai Teknologi MEPPO.

2. Hardono, ST, MT selaku KaSie Program dan Penerapan Teknologi Balai Teknologi MEPPO.

3. Khairul Jauhari, ST, MT selaku KaSie Kerjasama dan Pelayanan Jasa Teknologi Balai Teknologi MEPPO 
4. Albertus Rianto Suryaningrat, ST, MT selaku kepala lab Mesin Perkakas BTMEPPO

5. Seluruh staff lab mesin perkakas yang telah mendukung dalam penulisan jurnal ini.

\section{DAFTAR PUSTAKA}

1. Jedrzejewski, J., Kwasny, W., 2001, XII Workshop on Supervising and Diagnostic of Machining Systems, Wroclaw University of Technology.

2. Budak, E., Lazoglu, I., Guzel, B.U., 2004, Improving Cycle Time in Sculptured Surface Machining Through Force Modeling, Annals of the CIRP,53/1:103-106

3. Campomanes, M. L., Altintas, Y., 2003, An Improved Time Domain Simulation for Dynamic Milling at Small Radial Immersions, Trans.ASME,Manufacturing and Engineering and Science, 125(3):416-422

4. Y. Altintas, C. Brecher, M. Weck, S. Witt, Virtual machine tool, Annals of CIRP 54 (2005) 115-138
5. Weck, Manfred, Handbook of Machine Tools Volume 2: Construction and Mathematical Analysis, John Wiley \& Sons, Inggris, 1984.

6. Wibowo, Agus. Ahmad Taufiqur Rohman, Optimisasi Desain Ribbing pada Struktur Bed Mesin Bubut CNC terhadap Pengaruh Defleksi dan Frekuensi Pribadi, SNTM ITB (2016)

7. http://www.iron-foundry.com/cast-ironmechanical-properties.html, diakses tanggal 27 Juni 2019.

8. Joshi, PH., Machine Tools Handbook : Design and Operation, Tata McGrawHill, India, 2005.

9. Cook, R., Malkus, D., Plesha, M., 1988, Concepts and Applications of Finite Element Analysis, 3. Edition, John Wiley, Madison.

10. Weck, Manfred, Handbook of Machine Tools Volume 2: Construction and Mathematical Analysis, John Wiley \& Sons, Inggris, 1984. 